\title{
Metallographic Sample Preparation and Characterisation of Oxide Scales on Hot-Rolled Steel Strips
}

\author{
Oktay Elkoca ${ }^{1}$, Kemal Davut ${ }^{2,3}$ \\ 1 Eregli Iron and Steel Works, Inc., Hot Rolled Products and Process R\&D Dept., Eregli, \\ Zonguldak, Turkey \\ 2 Atılım University, Metal Forming Center of Excellence, Incek, Ankara, Turkey \\ 3 Atılım University, Department of Metallurgical and Materials Engineering, Incek, Ankara, \\ Turkey
}

Oxide scales are formed on the surface of steel strips after hot rolling process. Since they affect the subsequent processes such as cold rolling, forming as well as the pickling process, the characterization of those oxide scales formed on the hot-rolled strips is of great importance. The pickling process, in particular, has been reported to be influenced by the scale's properties such as grain size, grain boundary character and the nature of the present phases in a rather unique way [1].

The oxide scales are usually composed of three different iron oxide phases, i.e. hematite, magnetite and wustite; which are usually located on the top, in the middle, and at the bottom of the scale layer, respectively. Sometimes the bottom layer of the oxide scale might have decomposition products of the wustite [2]. Total thickness of the oxide scale is increased at higher finishing and coiling temperatures of hot rolling process. During the cooling of the strip after coiling, the oxide scale continues to grow at the edge as well as the head and tail ends of the strip, where oxygen is still available. Also, the scale undergoes structural changes during cooling, because the wustite phase is unstable below $570^{\circ} \mathrm{C}$. Previous examinations revealed that the thickness of the oxide layers at the edge region strongly depends on the coiling temperature, the shape of the hot rolled strip and the coil. The thick oxide layer could extend much further from the edges of the strips that have poor shapes, or that are being loosely wrapped. This causes insufficient pickling of the hot rolled strip during the pickling process (Fig. 1).

The oxide scales are far more brittle than the steel substrate at room temperature [3]; moreover the mechanical properties of the scale layers are different from each other. This causes the oxide scales to be cracked or fragmented into pieces during the sample preparation. The cracks associated with the sample preparation could possibly and falsely be treated as genuine cracks in the scale [4-7]. Therefore, the metallographic sample preparation process is rather difficult and particularly important $[8,9]$.

This work presents; firstly the metallographic specimen preparation procedures to preserve the true nature of oxide layers in a hot rolled strip; secondly the comparison of various methods to characterize the structures observed on the strip. Samples were cut from the regions across the width of a hot rolled strip of a commercial steel grade and they were characterized on the cross-sections perpendicular to the rolling direction. The metallographic sample preparation started with sectioning of samples cold-mounted in an epoxy resin by using an abrasive cutter. Grinding was performed using 320 grit and 600 grit SiC papers. Further grinding on finer abrasive papers (1000 grit, or 1200 grit) was found to be unnecessary. The most important step in the sample preparation was the coarse polishing step, which was preferably performed on a napless cotton cloth with a 6 micron diamond paste. The oxide scale layers were characterized by Nikon Eclipse MA200 optical light microscope 
(OLM), Jeol JSM 7001F Schottky field emission gun (FEG) scanning electron microscope (SEM), energy-dispersive X-ray spectroscopy (EDS) and Electron Back Scatter Diffraction (EBSD) technique. EBSD and EDS analysis were performed on the mentioned FEG-SEM equipped with Oxford INCA and CHANNEL 5 software packages.

As a summary, this paper presents the comparison of OLM, SEM, EDS and EBSD techniques to characterize the oxide scales on hot-rolled steel strip. In addition, metallographic specimen preparation methods to reveal the true nature of oxides are also presented. The OLM and EDS techniques struggle to differentiate the different oxide layers due to the similarity of the local chemical composition among them. On the other hand, EBSD can identify these oxide layers much successfully as their crystal structures are rather dissimilar. Moreover, EBSD can give further information about the grain structure and local misorientations present within different scale layers.

References:

[1]. M. Zhang, G. Shao, Materials Science and Engineering A, 452-453 (2007) 189-193, [2]. R. Y. Chen and W. Y. D. Yuen, Oxid. Met., 59 (2003), 433.

[3]. L. E. Samuels, Metallographic Polishing by Mechanical Methods, 3rd Ed., ASM, Ohio, (1982), 137.

[4]. A. U. Malik and D. P. Whittle, Oxid. Met., 16 (1981), 339.

[5]. H. T. Abuluwefa, R. I. L. Guthrie and F. Ajersch: Metall. Mater. Trans. A., 28A (1997), 1633.

[6]. M. G. Fontana, Corrosion Engineering, 3rd Ed., McGraw-Hill, New York, (1987), 509.

[7]. D. Caplan, G. I. Sproule, R. J. Hussey and M. J. Graham, Oxid. Met., 12 (1978), 67.

[8]. L. B. Pfeil, J. Iron Steel Inst., 123 (1931), 237.

[9]. L. Hachtel, Prakt. Metallogr., 32 (1995), 332.

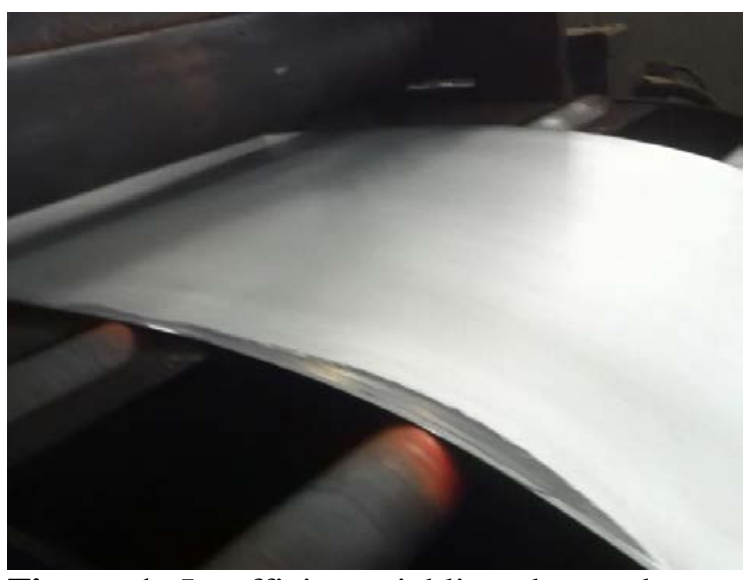

Figure 1. Insufficient pickling due to loose wrapping, observed on the edge region of a hot rolled strip.

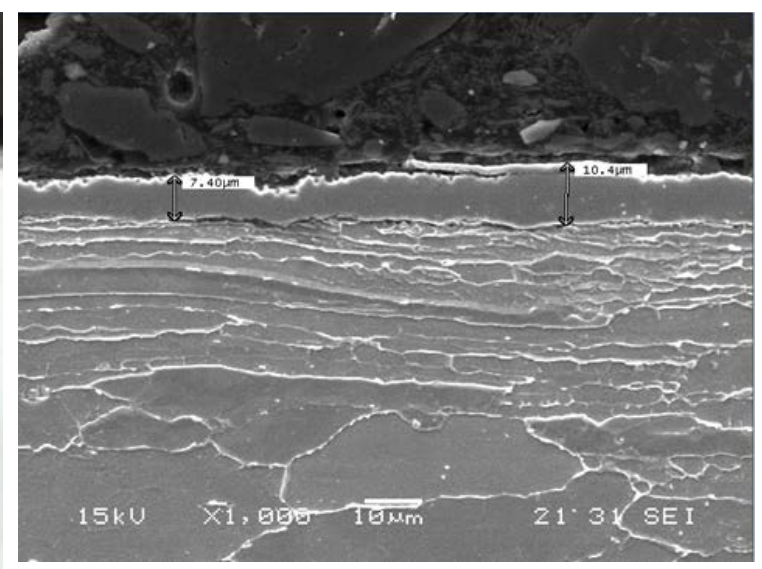

Figure 2. SEM micrograph of the sample taken from the edge region of the strip. 